\title{
Bettina Knapp, Marie Dorval: France's Theatrical Wonder
}

\section{Rita Severi}

\section{Q OpenEdition}

\section{Journals}

\section{Edizione digitale}

URL: http://journals.openedition.org/studifrancesi/8295

DOI: 10.4000/studifrancesi.8295

ISSN: 2421-5856

\section{Editore}

Rosenberg \& Sellier

\section{Edizione cartacea}

Data di pubblicazione: 1 mai 2009

Paginazione: 190-191

ISSN: 0039-2944

\section{Notizia bibliografica digitale}

Rita Severi, «Bettina Knapp, Marie Dorval: France's Theatrical Wonder», Studi Francesi [Online], 157 (LIII ! I) | 2009, online dal 30 novembre 2015, consultato il 12 janvier 2021. URL: http:// journals.openedition.org/studifrancesi/8295 ; DOI: https://doi.org/10.4000/studifrancesi.8295

Questo documento è stato generato automaticamente il 12 janvier 2021.

\section{(c) (i) $\odot$}

Studi Francesi è distribuita con Licenza Creative Commons Attribuzione - Non commerciale - Non opere derivate 4.0 Internazionale. 


\title{
Bettina Knapp, Marie Dorval: France's Theatrical Wonder
}

\author{
Rita Severi
}

\section{NOTIZIA}

BETTINA KNAPP, Marie Dorval: France's Theatrical Wonder, Chiasma 21, Amsterdam, Rodopi, 2007, pp. 234.

1 La vita dell'attrice drammatica Marie Dorval (1798-1849), nata e cresciuta in una famiglia di guitti, abituata a calcare le scene fin dalla tenera età di otto anni e a provvedere a sé stessa e alla sua famiglia come una donna emancipata dei giorni nostri, è narrata dalla Knapp con un ritmo e uno stile incalzante, particolarmente coinvolgente. Tutta la biografia è sorretta dall'idea di fondo che Marie Dorval, oltre a essere stata una star di primaria importanza nel teatro romantico, è soprattutto un esempio di grande, femminile intraprendenza e libertà. Già nella prefazione l'autrice ci ricorda che nel capolavoro cinematografico di Marcel Carné, Les Enfants du Paradis (1945), Arletty, che recita il ruolo dell'attrice brillante Garance, che attrae tutti coloro che la circondano, s'ispirò direttamente alla personalità magnetica della Dorval.

2 Infatti, appena la ventenne Marie giunge a Parigi, pur essendo ingenua, s'accorge d'essere dotata di grande fascino, soprattutto quando viene notata dall'influente direttore della Capella Reale, Alexandre Piccini. La Dorval ne diventerà l'amante e, in breve tempo, si troverà la strada spianata per il debutto al prestigioso teatro della Porte-Saint-Martin. La Dorval si esibirà raggiungendo un tiepido successo e l'ammirazione dell'impresario del teatro, Jean-Toussaint Merle col quale convolerà a nozze nel 1829, quando ormai si era guadagnata il plauso del pubblico più influente recitando ne L'Auberge des Adrets di Frédérick Lemaître, il quale, per un certo periodo, prima del matrimonio, fu anche suo amante (cap.3). La Dorval fu anche abile a cavalcare le diverse mode del periodo, come l'interesse per il teatro inglese che iniziò alla fine degli anni Venti, quando nel 1828 nei teatri di Parigi imperversava la 
«Shakespearemania» (p.75) e alcuni famosi attori inglesi, quali Kemble, Macready, Kean si esibirono recitando Amleto, Otello, Macbeth, Il mercante di Venezia, Re Lear. L'attrice è infatti spesso ricordata come una Lady Macbeth furiosa nel 1829 (p. 93).

Ella fu soprattutto la musa ispiratrice di alcuni grandi poeti e drammaturghi romantici. Faceva parte del salon dello scrittore anglofilo Charles Nodier e recitò nel suo dramma Le Vampire che ebbe notevole successo. Dumas la volle nella sua Christine, una tragedia storica che metteva in scena le vicissitudini di Cristina di Svezia. Alfred de Vigny, che l'ammirò come Lady Macbeth, cominciò a pensare che sarebbe stata anche una magnifica Portia o Giulietta. Vigny, che aveva tradotto Giulietta e Romeo, Otello e Il mercante di Venezia (p.96) ben presto intuì che la Dorval era una delle maggiori interpreti del teatro tragico e, per lei, compose il dramma passionale La Maréchale d'Ancre, uno spettacolo decoroso che fu un insuccesso finanziario. Fu in questo periodo che de Vigny s'accorse d'essersi follemente innamorato di Marie Dorval e che per mezzo della sua ossessione la sua vita era diventata più movimentata e intensa, proiettata verso «l'amore, l'invenzione, l'ammirazione» (p. 105 e capitoli 5-8). Fu solo con il dramma Chatterton che de Vigny ottenne il plauso del pubblico e Marie Dorval un ruolo degno delle sue doti melodrammatiche. La sconvolgente passione per de Vigny comunque non tolse a Marie l'inveterato gusto per gli amori occasionali: altri attori, artisti, giornalisti. Dorval ebbe un flirt impetuoso con Victor Hugo mentre recitava nel suo dramma, Angelo (p. 170 s.) e, dopo il 1833, secondo la Knapp, una sconvolgente affaire saffica con George Sand, allora ventinovenne. La scrittrice rimase letteralmente incantata dall'attrice. Arsène Houssaye le chiamò le inséparables e le descrisse mentre l'una scioglieva i capelli dell'altra prima di un abbraccio lesbico (p. 197). De Vigny, che non apprezzava George Sand, fu disgustato ma non soffrì perché ormai il suo amore per Marie era diventato insofferente. Negli ultimi anni della sua vita Marie Dorval tornò dal marito, dalle figlie e dall'amatissimo nipote che morì nelle sue braccia all'età di quattro anni, un anno prima della sua morte a 51 anni.

Bettina Knapp è una biografa dalla scrittura accattivante, ottima per chi è alla ricerca di una narrazione romanzata, ma insufficiente per chi desidera una ricostruzione documentata della vita di Marie Dorval che già in passato è stata oggetto di studi (Ambrière, Moser, Gaylor). Esiste una bibliografia finale, ma nel testo non vi sono note $\mathrm{e}$ le citazioni, stranamente, sono sempre riportate nella traduzione inglese, come pure i titoli dei numerosi drammi francesi. Non esiste un indice dei nomi né un'appendice che elenchi i ruoli, i drammi e i teatri che assicurarono una fama così duratura a Marie Dorval. 